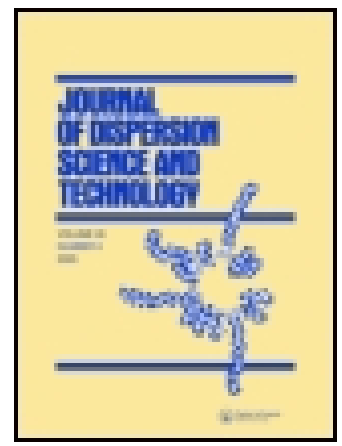

Journal of Dispersion Science and Technology

ISSN: (Print) (Online) Journal homepage: https://www.tandfonline.com/loi/ldis20

\title{
Nanohydroxyapatite (n-HAp) as a pickering stabilizer in oil-in-water (O/W) emulsions: a stability study
}

Andreia Ribeiro, Yaidelin A. Manrique, Isabel C.F.R Ferreira, Maria Filomena Barreiro, José Carlos B. Lopes \& Madalena M. Dias

To cite this article: Andreia Ribeiro, Yaidelin A. Manrique, Isabel C.F.R Ferreira, Maria Filomena Barreiro, José Carlos B. Lopes \& Madalena M. Dias (2020): Nanohydroxyapatite (n-HAp) as a pickering stabilizer in oil-in-water $(\mathrm{O} / \mathrm{W})$ emulsions: a stability study, Journal of Dispersion Science and Technology, DOI: 10.1080/01932691.2020.1845199

To link to this article: https://doi.org/10.1080/01932691.2020.1845199

\section{Published online: 20 Nov 2020.}

Submit your article to this journal $\pi$

Џ Article views: 95

Q View related articles $\sqsubset$

View Crossmark data ¿ 


\title{
Nanohydroxyapatite (n-HAp) as a pickering stabilizer in oil-in-water (O/W) emulsions: a stability study
}

\author{
Andreia Ribeiro $^{\mathrm{a}, \mathrm{b}}$ (D), Yaidelin A. Manrique ${ }^{\mathrm{a}, \mathrm{b}}$ (D), Isabel C.F.R Ferreira ${ }^{\mathrm{b}}$ (D), Maria Filomena Barreiro ${ }^{\mathrm{b}}$ (D), \\ José Carlos B. Lopes ${ }^{a}$ iD, and Madalena M. Dias ${ }^{a}$ \\ aLaboratory of Separation and Reaction Engineering - Laboratory of Catalysis and Materials (LSRE-LCM), Faculdade de Engenharia, \\ Universidade do Porto, Porto, Portugal; ${ }^{b}$ Centro de Investigação de Montanha (CIMO), Instituto Politécnico de Bragança, Campus de Santa \\ Apolónia, Bragança, Portugal
}

\begin{abstract}
Surfactant-free emulsions, such as Pickering emulsions, have been gaining an increased interest. They constitute green alternatives to the current industrial practices in emulsion technology finding diverse technological uses. In this work, nano-hydroxyapatite (n-HAp) was tested as an oil-inwater $(\mathrm{O} / \mathrm{W})$ Pickering stabilizer using a chemical system comprising sunflower oil at different $\mathrm{O} / \mathrm{W}$ ratios (10/90 to 60/40) and $\mathrm{n}$-HAp at concentrations ranging from 0.5 to $15 \mathrm{wt} \%$. The produced emulsions were characterized, and stability evaluated over a two-month period. Based on the results achieved for the $20 / 80$ series, a model to predict the emulsion stability taking into account the O/W ratio, total solids content, droplet diameter, and n-HAp dimensions, was developed. CryoSEM evidenced the attachment of n-HAp particles at the oil surface (oil core-n-HAp shell morphology), corroborating their role as Pickering stabilizers. The experimental results, versus the predicted results were compared using a ternary phase diagram, which evidenced the formation of three zones (unstable, stable and gel) depending on the used O/W ratio and n-HAp concentration. Moreover, the comparison of the predicted with the obtained experimental data validated the model predictability.
\end{abstract}

GRAPHICAL ABSTRACT
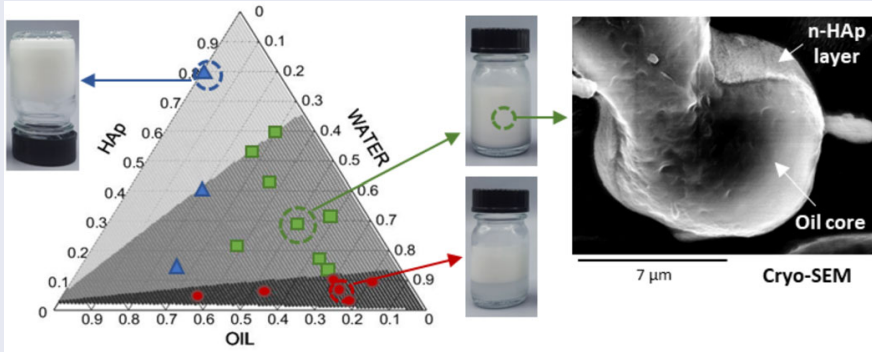

\section{Introduction}

Emulsions are mixtures of two immiscible liquids, oil and water, traditionally stabilized by one or more synthetic emulsifiers. However, some of these emulsifiers have been associated with allergic reactions and carcinogenicity, leading to health problems. ${ }^{[1]}$ In this context, Pickering emulsions, which are based in nontoxic solid particles, have started to appear as alternatives. ${ }^{[2]}$ In Pickering emulsions, solid particles get attached at the interface between the two immiscible liquids, stabilizing the emulsified droplets against coalescence. ${ }^{[3]}$

The first mention to Pickering emulsions dates from the $1900 \mathrm{~s},{ }^{[4,5]}$ and since then an increased interest has been

\section{ARTICLE HISTORY}

Received 12 May 2020

Accepted 12 October 2020

\section{KEYWORDS}

Surfactant-free emulsions; pickering emulsions; hydroxyapatite nanoparticles; O/W emulsions; emulsions stability 
suitable to stabilize water-in-oil (W/O) emulsions. ${ }^{[3]}$ However, some works also reported that the type of formed emulsions, and associated stability, depends on other parameters, such as the oil-water ratio and solids content. ${ }^{[10]}$ The assortment of studied Pickering stabilizers comprises organic and inorganic solid particles, such as modified silica, ${ }^{[11]}$ protein and polysaccharide-based particles, ${ }^{[12,13]}$ and fat crystals. ${ }^{[14]}$

Hydroxyapatite $\left(\mathrm{Ca}_{10}\left(\mathrm{PO}_{4}\right)_{6}(\mathrm{OH})_{2}\right)$ is widely used in the biomedical and biotechnological fields, due to its excellent biocompatibility, since it is the main component of both human bones and teeth. ${ }^{[15]}$ Recently, this material started to be described as a suitable Pickering stabilizer, which due to its hydrophilicity tends to stabilize O/W emulsions. ${ }^{[10,15]}$ In this scope, some authors have developed Pickering emulsions stabilized by HAp particles, in most cases combined with other polymers. Fujii, et al., ${ }^{[16]}$ Zhang, et al. ${ }^{[10]}$ and Okada, et al. ${ }^{[1]}$ produced microspheres via Pickering emulsion by using n-HAp dispersed in the aqueous phase and poly-e-caprolactone (PCL), poly-L-lactic acid (PLLA) and polystyrene dissolved in the oil phase. Zhang, et al. ${ }^{[15]}$ and $\mathrm{Hu}$, et al. ${ }^{[6]}$ evaluated the effect of HAp surface modification with stearic acid and sodium oleate, respectively, aiming at improving Pickering emulsions stability. Samanta, et al. ${ }^{[18]}$ and $\mathrm{Hu}$, et al. ${ }^{[19]}$ prepared nanocomposite scaffolds using Pickering emulsions as templates. In these two works, HAp was functionalized with PCL and PLLA in order to ensure emulsion stability during the scaffolds development.

To stabilize a Pickering emulsion, the solid particles should be irreversibly anchored at the oil or water surface to form a steric barrier. ${ }^{[20]}$ In this regard, some authors explained the Pickering emulsion stabilization mechanism through theoretical approaches and thermodynamic calculations based on the nature of the interactions between the liquids and the solid surface. For that Young equation was applied using surface energy considerations in order to interpret the interactions between the solid particles and the two liquid phases, and, consequently, to predict the contact angles. ${ }^{[21-24]}$

Formation and stability of Pickering emulsions depends on various factors such as particle wettability, particle concentration, particle size and shape, coverage density and $\mathrm{pH}$ of the aqueous phase. ${ }^{[25]}$ Previous studies have shown that there is a correlation between droplet size and particle concentration, and, consequently, with emulsion stability, ${ }^{[7,26]}$ and a model to predict particle's concentration at the core surface was developed. This model is based on the simple mass-balance, based on the argument that particles show similar behavior to surfactants when electrostatic repulsion is suppressed ${ }^{[25,27]}$ and considering that Pickering emulsions undergo "limited coalescence" during emulsification. ${ }^{\text {[27-29] }}$ Thus, the interfacial area, created during emulsification, should be larger than the area that can be covered by the particles, so that when stirring stops, in order to reduce the interfacial area, the droplets coalesce until the oil/water interface is adequately covered by the particles. ${ }^{[7,27,28,30]}$ When this phenomenon occurs, the emulsion has a unimodal droplet size distribution that is directly related to the particle mass and droplet coverage by ${ }^{[7]}$

$$
\frac{1}{D}=\frac{m_{p} a_{p}}{6 C \rho_{p} V_{d} v_{p}}
$$

where $D$ is the final drop diameter, $m_{p}$ is the mass of particles, $C$ is the surface coverage (the fraction of the interfacial area covered by the particles), $\rho_{p}$ is the particle density, $V_{d}$ is the volume of dispersed phase, $a_{p}$ is the particle area projected on the interface and $v_{p}$ is the particle volume. However, this equation can be applied only if: (i) the particles are completely and irreversibly attached at the surface; (ii) the emulsification process produce more oil/ water interface than what the particles can cover; (iii) the emulsion is produced with intermediate particle concentration; and (iv) electrostatic repulsion is suppressed. ${ }^{[7,25,28]}$

At low solid particles concentration, instability is often observed due to a lack of particles to stabilize the droplets. ${ }^{[7]}$ At high solid particles concentration, there is an excessive number of particles compared to the oil/water interfacial area created during the emulsification process. In this case, the stabilization can occur in different ways: (i) the droplets formed during the emulsification process are stabilized right away inducing size heterogeneity, or (ii) constant droplet sizes are obtained but particles are in excess in the continuous phase leading to a network in the continuous phase that can improve the emulsion stability. ${ }^{[7,31]}$ Arditty, et al. ${ }^{[28]}$ have shown that when a low $\mathrm{SiO}_{2}$ solid particle concentration is used, the emulsion droplet surface is not covered completely and droplet coalescence occurred, destabilizing the emulsion system. Aveyard, et al. ${ }^{[32]}$ found that with an increase of the $\mathrm{SiO}_{2}$ particle concentration, up to $3 \%$, the droplet size of the emulsion decreases; however, further increase in particle concentration does not change the droplet diameter, and the particles in excess stay dispersed in the continuous phase. Recently, Liu and Tang ${ }^{[20]}$ also determined the percentage of soy glycinin particle's surface coverage and particle centre-to-centre distance. The extent of surface coverage was obtained directly from the ratio between the potential coverage area of the soy glycinin particles, and the total interfacial area of the emulsion droplets. Additionally, and in order to describe the packing of the particles at the interface, the distance between them was estimated using two models (square and regular hexagonal array models).

The aim of this work was to develop stable oil/water Pickering emulsions using n-HAp particles as stabilizers. The impact of process parameters, such as oil-water ratio, solids (n-HAp) content, on emulsion stability through the evaluation of phase separation by creaming or sedimentation occurrence, were studied. Pickering emulsions were characterized in terms of particle's size and shape by laser diffraction techniques and microscopy and studied concerning their rheological behavior. The emulsion stability as function of the oil-water ratio and n-HAp concentration was evaluated after 2 days, 2 weeks, and 2 months. In order to predict the formation and stability of n-HAp Pickering emulsions a 


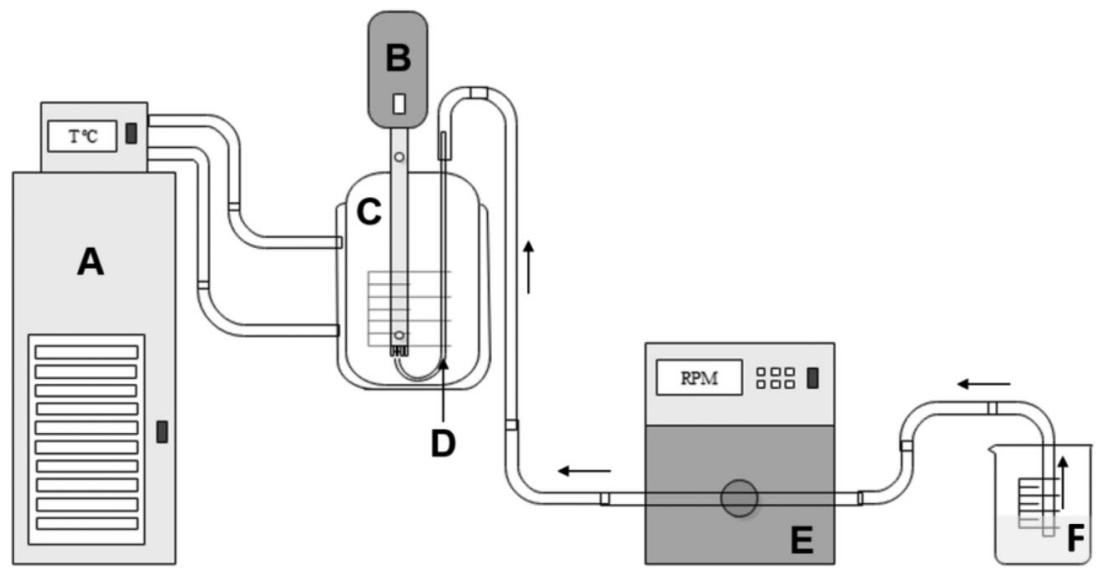

Figure 1. Experimental setup used to prepare $n-H A p$ dispersions and Pickering emulsions. A) thermostatic bath, B) rotor-stator homogenizer, C) mixing reactor, D) feeding channel, E) peristaltic pump, and F) Beaker with n-HAp paste or oil.

model was developed and compared with the experimental results.

The work reports experimental data on emulsions preparation and characterization covering a wide range of conditions and introduces a model to explain the observed stability behavior. To the best of our knowledge this is the first work reporting a model where n-HAp was used as Pickering stabilizers and that emulsion stability can be predicted with a model that takes into account the oil-water ratio, total solids content, droplet diameter, and n-HAp dimensions. Thus, this work is a step forward in the field of synthetic surfactants substitution contributing for the sustainable development of emulsions, which might find use in a wide range of applications, namely, to act as vehicles to support the delivering of functionalities.

\section{Experimental methods}

\subsection{Standards and reagents}

NanoXIM-CarePaste used in this work was supplied by Fluidinova S.A. (www.fluidinova.com). ${ }^{[33]}$ According to the technical information provided by Fluidinova, NanoXIMCarePaste is composed by $15.5 \pm 0.5 \mathrm{wt} \%$ of $\mathrm{n}-\mathrm{HAp}$ particles with typical size below $50 \mathrm{~nm}$ in a rod-like shape, and $4.5 \pm 0.5 \mathrm{wt} \% \mathrm{KCl}$. The water content is $\leq 81.0$ (wt $\%$ ). This $\mathrm{n}$-HAp paste was chosen due to its readily commercial availability. The presence of $\mathrm{KCl}$ in the nanoXIM-CarePaste is a result of its synthesis process, and in this work this paste was used as such.

Distilled water, treated in a Milli-Q water purification system (TGI Pure Water Systems, Greenville, SC, USA), was used as the aqueous phase. Sunflower oil was purchased from a local supermarket and used as the oil phase. It is a food grade vegetable oil obtained from sunflower seeds and mainly constituted by polyunsaturated fatty acids.

\subsection{Preparation of the pickering emulsions}

Emulsions preparation comprised two steps, namely the preparation of the n-HAp dispersions, followed by oil addition to form the final Pickering emulsion. The experimental set-up is similar to the one developed by Ruphuy, et al. ${ }^{[34]}$ (Figure 1). In the first step, the n-HAp aqueous paste was dispersed in water at different concentrations using a rotorstator homogenizer (Miccra RT D-9, Mülheim, Germany) to ensure nanoparticles dispersion. Briefly, the n-HAp paste was injected into the reaction vessel (C) containing the water, through a feeding channel (D) using a peristaltic pump at $240 \mathrm{pm}(43 \mathrm{~mL} / \mathrm{min}, \mathrm{E})$. The roto-stator homogenizer device (B) was set-up to operate at $39,000 \mathrm{rpm}$ during 4 min. Additionally, a thermostatic bath (A) was coupled to the system to ensure temperature control of the reaction vessel $\left(20^{\circ} \mathrm{C}\right)$.

In the second step, the sunflower oil was fed drop-wise into the previously prepared n-HAp aqueous dispersion using a peristaltic pump (E) operating at $240 \mathrm{rpm}$. The emulsification step was carried out using a rotor-stator homogenizer (B); after the oil addition, the system was kept under stirring, set to operate at $11,000 \mathrm{rpm}$ during $4 \mathrm{~min}$ and constant temperature $\left(20^{\circ} \mathrm{C}\right)$.

Various n-HAp concentrations (water-basis, wt $\%$ ) and oil-water ratios (defined as the ratio between the oil and the water phases, $v / v$ ) were tested. The concentration of $\mathrm{n}$-HAp ranged from $0.5 \mathrm{wt} \%$ to $15 \mathrm{wt} \%$ (water phase-basis), with $15 \mathrm{wt} \%$ corresponding to the original paste, and the lower concentrations were obtained by dilution. The oil-water ratio ranged from $10 / 90$ to $60 / 40(v / v)$. Table 1 summarizes the tested formulations. The experimental assays were based on a $400 \mathrm{ml}$ total volume scale of the aqueous phase. All emulsions were prepared in duplicate.

\subsection{Characterization of the pickering emulsions}

The produced emulsions were classified as $\mathrm{O} / \mathrm{W}$ or $\mathrm{W} / \mathrm{O}$ type by using the conventional emulsion drop test. ${ }^{[15]}$ This test evaluates the emulsion behavior upon in contact with the two used phases (oil and water). If the Pickering emulsion drop is rapidly dispersed in water and remains agglomerated in the oil phase, it is $\mathrm{O} / \mathrm{W}$ type; otherwise, it is a W/ $\mathrm{O}$ emulsion. To perform this test, $2-3$ emulsion drops were added to the water and oil phases followed by gentle stirring before visual inspection. 
Table 1. Pickering emulsions: n-HAp concentrations and oil-water ratio.

\begin{tabular}{lcc}
\hline Type of HAp paste & $\begin{array}{c}\text { Oil-water } \\
\text { ratio }(\mathrm{v} / \mathrm{v})\end{array}$ & $\mathrm{n}$-HAp concentration $(\mathrm{wt} \%)$ \\
\hline nanoXIM-CarePaste & $10 / 90$ & $1.5,5.0,10$ \\
& $20 / 80$ & $0.5,1.5,2.0,2.5,3.0,5.0,7.0,10,15$ \\
& $40 / 60$ & $1.5,5.0,10$ \\
$60 / 40$ & $1.5,5.0,10^{*}$ \\
\hline
\end{tabular}

*Not used due to preparation difficulties.

The stability of the produced Pickering emulsions was checked immediately after preparation (0 days) and monitored along the storage time (a total time-frame of two months was used with sampling at 2 days, 2 weeks, and 2 months). Instability occurrence (creaming or sedimentation) was visually checked and photographically registered the evolution with a Nikon digital camera (Nikon D3400, Tokyo, Japan). In parallel, emulsion's morphology was checked by optical microscopy (OM) using a Carl Zeiss Axiotech $100 \mathrm{HD}$ microscope (Zeiss Instruments, Jena, Germany) equipped with a digital camera (AxioCam 105 color; Zeiss Instruments, Jena, Germany). To perform these analyses, a sample aliquot was placed on a microscope slide, then gently covered with a coverslip. Image acquisition and processing were performed using Zen software (2.3; blue edition). Both transmitted and reflected light modes were used. Complementary, size distributions were determined from fresh Pickering emulsions using laser diffraction through coulter (LS230 Series instruments, Brea, California) and the corresponding average size (in volume) was calculated.

Cryo-SEM (Cryo- Scanning Electron Microscopy) was used to inspect the morphology of the produced Pickering emulsions. The analyses were carried out in a high-resolution scanning electron microscope (JEOL JSM 6301 F, Washington, USA), with X-ray microanalysis (Oxford INCA Energy 350, Wiesbaden, Germany), and CryoSEM experimental facilities (Gatan Alto 2500, München, Germany). The sample was rapidly cooled by plunging it into subcooled nitrogen and then transferred under vacuum to the cold stage of the preparation chamber. Thereafter, the sample was fractured, sublimated $\left(180\right.$ seconds at $\left.-90^{\circ} \mathrm{C}\right)$, and coated with $\mathrm{Au} / \mathrm{Pd}$ (45 seconds under $12 \mathrm{~mA}$ current). Finally, the sample was transferred into the SEM chamber and observed at $-150^{\circ} \mathrm{C}$. This characterization was intended to check the successful formation of the emulsion droplets and their coverage with the n-HAp Pickering particles. This analysis was performed with the sample prepared with an $\mathrm{O} / \mathrm{W}$ ratio of $20 / 80$ and $5 \mathrm{wt} \% \mathrm{n}-\mathrm{HAp}$.

Rheological studies were carried out to understand the impact of the n-HAp concentration and the oil volume fraction on the viscous and viscoelastic behavior of the produced emulsions. The tests were done using an Anton Paar rheometer (Anton Paar, GmbH, Austria) with a parallel plate. All measurements were made with a fixed gap of $0.5 \mathrm{~mm}$ and at $20^{\circ} \mathrm{C}$. The viscosity measurements of the Pickering samples were determined as a function of the shear rate in a range from 500 to $4500 \mathrm{1} / \mathrm{s}$. The frequency sweep was oscillated from 0.3 to $100 \mathrm{rad} / \mathrm{s}$, and all measurements were performed within the determined linear viscoelastic region (LVE) and made at $0.1 \%$ strain. Data is reported as elastic or storage modulus $\left(\mathrm{G}^{\prime}\right)$ or loss modulus $\left(\mathrm{G}^{\prime \prime}\right)$ as a function of frequency.

\section{Results and discussion}

\subsection{Morphology of the formed pickering emulsions}

All the produced emulsions were of $\mathrm{O} / \mathrm{W}$ type, as checked by the drop test (i.e., all the emulsions droplets dispersed in water medium). Moreover, Figure 2 shows Cryo-SEM images obtained for a fractured cross-section of the frozen Pickering emulsion using an oil-water ratio of 20/80 and $5 \mathrm{wt} \%$ of $\mathrm{n}$-HAp. Cryo-SEM is one of the few techniques available to visualize the interfacial structure of emulsions stabilized by solid particles. ${ }^{[35]}$ During sample preparation, namely during the sublimation step, the water phase is evaporated while the oil phase remains. Figure $2 \mathrm{~A}$, B show frozen Pickering droplets at $1000 \times$ and $3000 \times$ magnification, respectively. Some non-spherical shape and incomplete Pickering droplets were observed, which can be explained by the freezing and fracturing of the sample, which in some cases, also implies the fracturing of the n-HAp layer, resulting in the exposure of the oil core. Additionally, the continuous phase is characterized by the presence of striations, which can be related with the excess of n-HAp remaining free in the continuous phase or due to slow freezing, which may lead to the formation of salt crystals since the n-HAp paste has $\mathrm{KCl}$. Previously, Binks and Kirkland ${ }^{[35]}$ documented the presence of striations in cryo-SEM images of the Pickering emulsions and related their presence with the use of excessive solid particles. Griffith and Daigle ${ }^{[36]}$ also showed the presence of the striations (referred as a bridged network) on the continuous phase of the Pickering emulsion and related it as excessive solid particles. They also concluded that these solid particles were responsible for inhibiting long term emulsion creaming and coalescence. Figure $2 \mathrm{C}$ details a single Pickering droplet and the respective EDS (Energy Dispersive X-Ray Spectroscopy) analysis acquired in two different points - outside (spectrum 1) and inside (spectrum 2) of the droplet. From the droplet observation, it is possible to view a white layer around the oil droplet, evidencing that the n-HAp particles were attached to the oil droplet surface. In agreement with paste composition, spectrum 1 shows the presence of $\mathrm{n}-\mathrm{HAp}$ and $\mathrm{KCl}$ salt in the layer structure through the presence of oxygen $(\mathrm{O})$, phosphorus $(\mathrm{P})$, calcium $(\mathrm{Ca})$, potassium $(\mathrm{K})$ and chloride $(\mathrm{Cl})$. Spectrum 2, taken inside the droplet, indicates the presence of oil through at the existence of just carbon (C), and oxygen $(\mathrm{O})$ the major elements in the oil (triacylglycerol). Thus, this analysis confirmed that the particles had an oil core covered by a n-HAp shell (shell-like morphology). The presence of the $\mathrm{Au}$ and $\mathrm{Pd}$ elements result from the used coating process. An estimate of the n-HAp shell thickness was obtained through the measurement of the white border of a Pickering droplet resulting on an average value of $200 \mathrm{~nm}$. This value indicates a thickness higher than one individual $\mathrm{n}$-HAp (4-fold the dimensions of a n-HAp particle, which is 

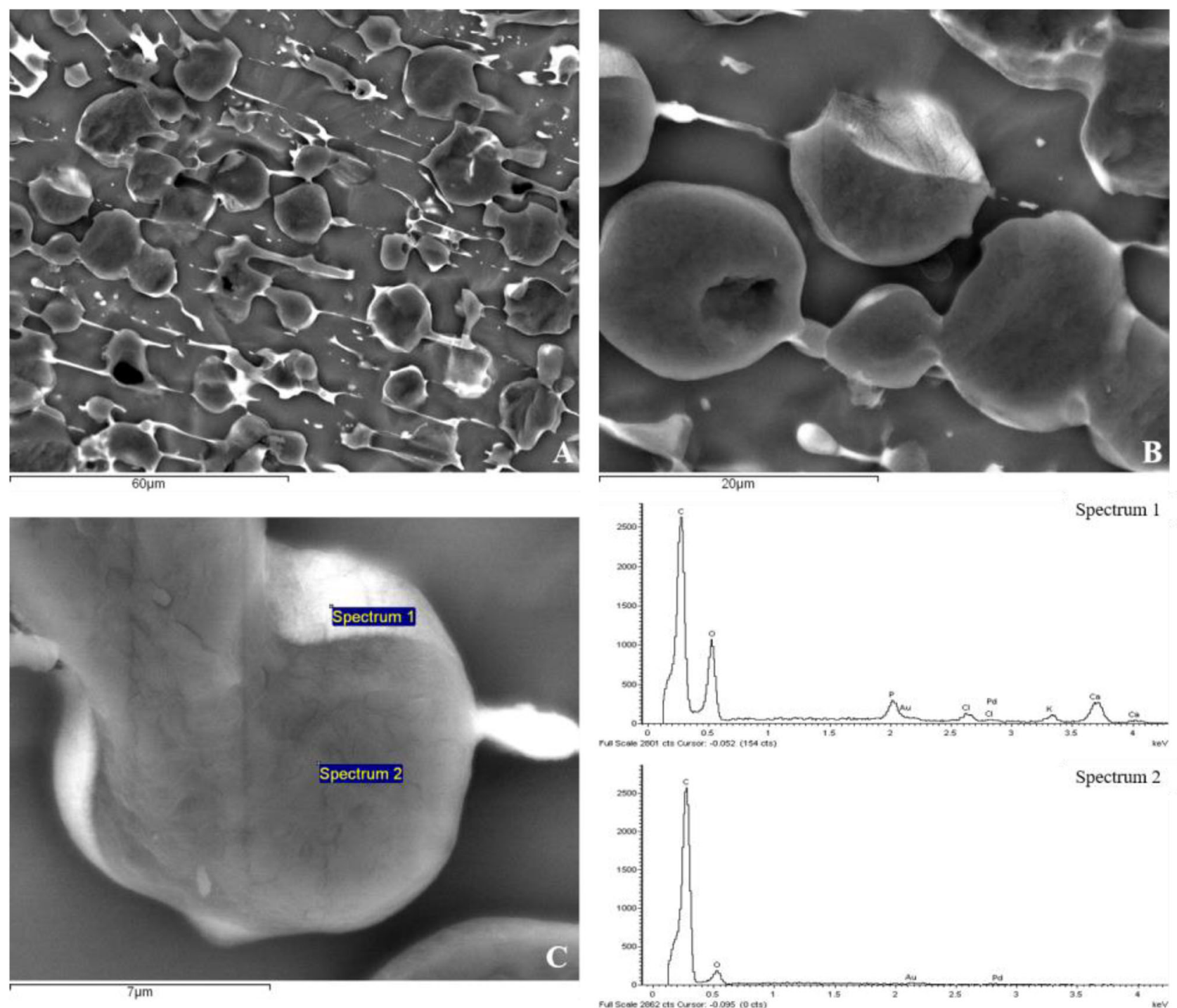

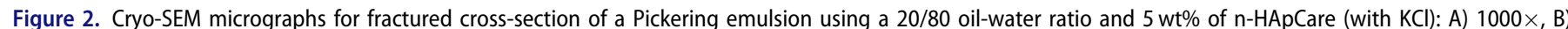
$3000 \times$ and C) $8000 \times$. The two EDS spectra correspond to the identified points in image C (spectrum 1 and spectrum 2). All micrographs were obtained with $15 \mathrm{Kv}$.

around $50 \mathrm{~nm}$ ), meaning that deposition of multiple n-HAp layers has occurred.

\subsection{Analysis of phase separation}

Phase separation is a catastrophic phenomenon for any emulsified product, compromising its shelf-life. Thus, stability under storage conditions is a key parameter to study since it determines, to some extent, if the product is suitable for a given application. ${ }^{[37]}$

\subsubsection{Effect of $n-H A p$ concentration}

To evaluate the effect of $n$-HAp concentration in the stability of Pickering emulsions, the oil-water ratio was fixed at 20/80 $(v / v)$ with n-HAp concentration varying between 0.5 to $15 \mathrm{wt} \%(0.5,1.5,2.0,2.5,3.0,5.0,7.0,10$, and $15 \mathrm{wt} \%)$. The stability of the prepared Pickering emulsions was monitored along a two-month period under storage at room temperature and natural light exposure. Production of emulsions in the absence of n-HAp particles (control emulsions) was also performed in the testing of the mixing system, leading to the expected phase separation within a short timeframe (data not shown).

Figure 3 shows the optical microscopy images of the Pickering emulsions produced with different $n-H A p$ concentrations as a function of storage time. All images were obtained with a magnification of $20 \times$. Right after the emulsification step (0 days), all the produced Pickering emulsions presented a morphology characterized by spherical shape and individualized droplets with a size ranging from 10 to $25 \mu \mathrm{m}$ (values corroborated by laser diffraction from the average size in volume). Moreover, the data obtained by laser diffraction (Table 2) puts in evidence the decrease trend of the mean droplet size as the n-HAp content increases. However, at low n-HAp concentration (1.5 wt\%), the emulsions become unstable after a short period of time, as can be observed in the OM image acquired after 2 days (Figure $3-1.5 \mathrm{wt} \% \mathrm{n}$-HAp), where larger and irregular shaped droplets can be observed, pointing out to the occurrence of coalescence. For this n-HAp concentration, this phenomenon increased along storage time, becoming highly 


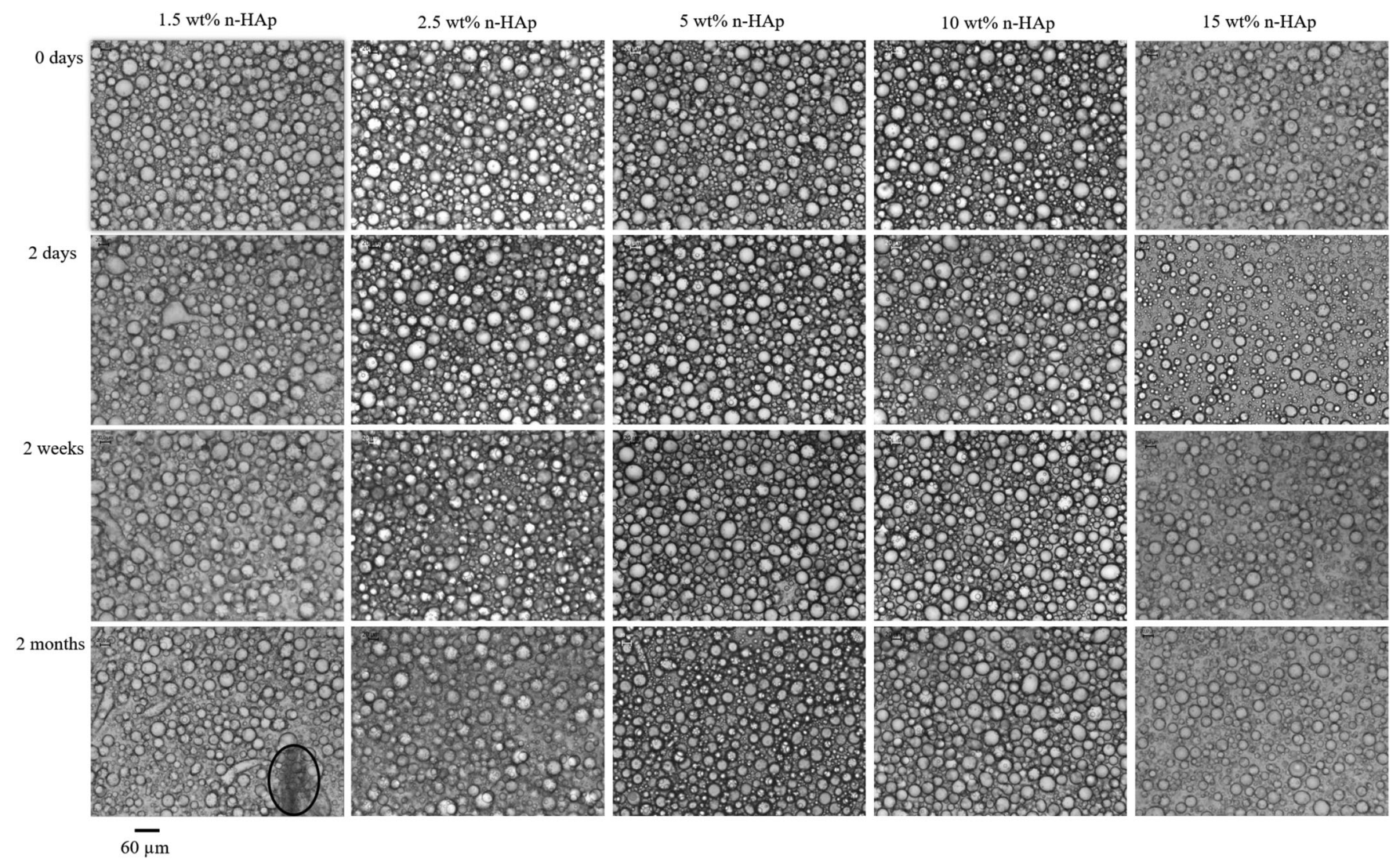

Figure 3. OM images, acquired in transmitted light mode, of Pickering emulsions stabilized with different $\mathrm{n}$-HAp concentrations and fixed oil-water ratio (20/80, $v /$ v). All images were registered at $20 \times$ magnification. The circle on the 2 -month $1.5 \mathrm{wt} \%$ image shows regions of $\mathrm{n}$-HAp agglomeration.

TABLE 2. Effect of $\mathrm{n}$-HAp concentration and oil-water ratio in the mean droplet size right after preparation and at the end of the study period ( 2 months).

\begin{tabular}{|c|c|c|c|}
\hline & \multirow[b]{2}{*}{$n$-HAp concentration } & \multicolumn{2}{|c|}{ Mean Droplet Size $(\mu \mathrm{m})$} \\
\hline & & 0 days & 2 months \\
\hline Fixed oil-water ratio & $1.5 \mathrm{wt} \%$ & 20.5 & - \\
\hline \multirow[t]{4}{*}{$20: 80$} & $2.5 \mathrm{wt} \%$ & 19.4 & - \\
\hline & $5.0 \mathrm{wt} \%$ & 18.4 & 18.6 \\
\hline & $10 \mathrm{wt} \%$ & 15.9 & 15.4 \\
\hline & $15 \mathrm{wt} \%$ & 14.7 & 14.5 \\
\hline Fixed $n$-HAp concentration & Oil-water ratio & 0 days & 2 months \\
\hline \multirow{4}{*}{$5 \mathrm{wt} \%$} & 10:90 & 12.7 & - \\
\hline & $20: 80$ & 18.4 & 18.6 \\
\hline & $40: 60$ & 19.5 & 19.7 \\
\hline & $60: 40$ & 23.1 & 23.0 \\
\hline
\end{tabular}

- Not evaluated since the emulsion become instable (phase separation).

noticeable after the two-month period, together with n-HAp particles agglomeration which is visually associated with the presence of darker regions in the microscopy images. On the other hand, stable Pickering emulsions were obtained for higher n-HAp concentrations. For example, when $5 \mathrm{wt} \%$ was used, individual and spherical droplets were observed along the examined storage time, i.e., particles retained their initial size and shape. In these cases, the absence of coalescence was noticed, meaning that higher n-HAp concentrations, in this study up to $10 \mathrm{wt} \%$, favored Pickering emulsion stability. Gel-like Pickering emulsions were achieved when $\mathrm{n}$-HAp was used at $15 \mathrm{wt} \%$ concentration. The stability of the Pickering emulsions can also be verified through the evaluation of the data in Table 2 , where it is possible to observe the maintenance of the mean droplet size for the stable Pickering emulsions along the timeframe of storage.

Macroscopically, initially all the prepared Pickering emulsions were homogenous, i.e., no phase separation was observed. However, after two days, phase separation started to be observed for emulsions prepared with $1.5 \mathrm{wt} \%$ of $\mathrm{n}$ HAp, and after 2 weeks for the ones prepared with $2.5 \mathrm{wt} \%$. In these cases, a layer at the top of the emulsion (creaming) was observed.

The presence of $\mathrm{KCl}$ in the used $\mathrm{n}-\mathrm{HAp}$, which is associated with its synthesis process, might also help to promote emulsion stabilization, as previously reported. ${ }^{[38,39]}$ Nevertheless, the concentration of the used solid particles was also reported to significantly affect Pickering emulsions stability, as well as the obtained droplet size, as was also verified in the present work. For example, Zhang, et al. ${ }^{[10]}$ showed that the n-HAp concentration had a fundamental role in their stabilization since stable emulsions were only achieved when high concentrations were used. The same behavior was verified with studies using other solid particles such as soy glycinin, starch nanocrystals and hemp powder. ${ }^{[20,40,41]}$ Moreover, the droplet size of Pickering emulsions decreased with the increase of particle's concentration with a consequent improvement of the emulsion stability. ${ }^{[20,40,41]}$

\subsubsection{Effect of oil-water ratio}

The effect of the oil-water ratio on the Pickering emulsion stability was evaluated by studying oil-water ratios of $10 / 90$, 


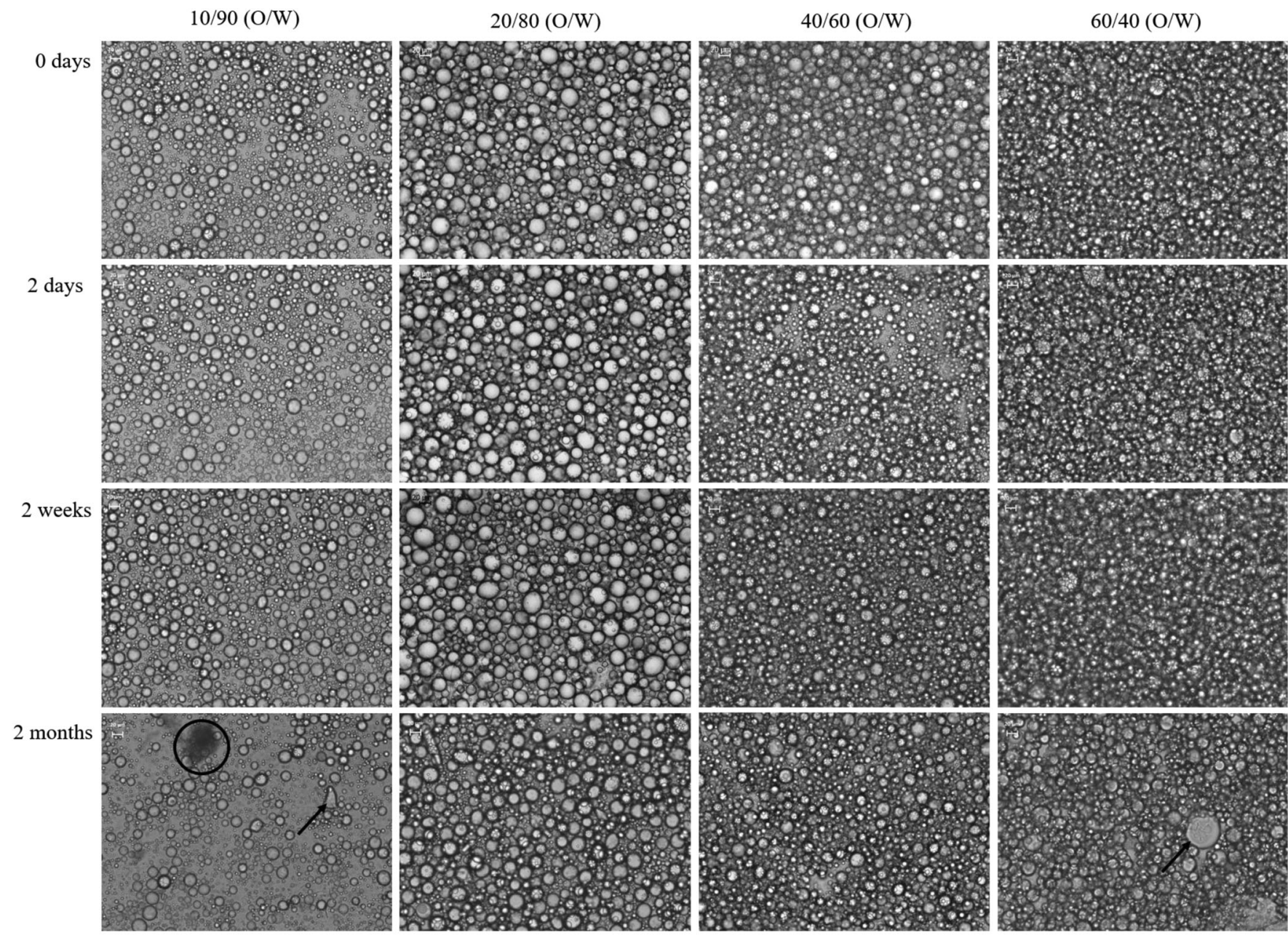

$6 \overline{\mathrm{\mu m}}$

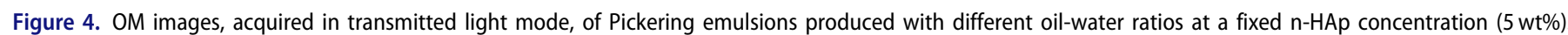
All images were registered at $20 \times$ magnification. The arrows indicate large oil droplets and the circles indicate dark regions associated with $\mathrm{n}$-HAp agglomeration.

20/80, 40/60 and 60/40 at a fixed n-HAp concentration of $5 \mathrm{wt} \%$.

Figure 4 shows the obtained OM images along the twomonth period evaluation. For the whole range of tested oilwater ratios, well-defined droplets right after emulsification (0 days) were observed. Comparing different oil-water ratios, and as expected, it is possible to observe that higher values lead to a higher number of droplets. Namely, in the 60/40 ratio images, dense emulsions with tightly packed droplets are perceived. This effect was also observed by Yang, et al. ${ }^{[40]}$ for Pickering emulsions with other solid particles (starch nanocrystals). Concerning the size of the droplets, a range between 13 and $23 \mu \mathrm{m}$ was observed (corroborating by laser diffraction from the average size in volume). Through the analysis of mean droplet size obtained by laser diffraction (Table 2), it is possible to corroborate that the increase of the oil-water ratio leads to an increase in mean droplet size. Moreover, for the stable Pickering emulsions, the mean droplet size was observed to remain unaltered along the 2-months period study.

Regarding emulsion stability, Zhang, et al., ${ }^{[10]}$ who produced Pickering emulsions with HAp particles and PLLA, and dichloromethane as the oil phase, reported that emulsion stability increased with the decrease of oil-water ratio, however, the emulsions did not exceed a stability of 6 days. The authors justified this fact with the hydrophilicity of HAp since it is easier to prepare stable O/W (from 10 to 60 oil volume fraction) instead of W/O emulsions (from 70 to 90 oil volume fraction). In this work, all emulsions (from 10 to 60 oil volume fraction) were stable for up to onemonth. However, the emulsions prepared using 10/90 oilwater ratio showed signs of destabilization after two months. This could be observed by visual inspection (creaming appearance) and also by the appearance of n-HAp agglomerates and oil segregation, as identified in the OM images of Figure 4 through the presence of darker regions and large oil droplets, respectively.

Although the emulsion prepared with a 20/80 as well as $60 / 40$ oil-water ratios showed some coalescence, in particular of small droplets, this occurrence was not enough to destabilize the emulsion. Samples were also analyzed through $\mathrm{OM}$ in reflected light mode. Figure 5 compares two different Pickering emulsions, namely the ones with 10/90 and 20/80 oil-water ratios, at times 0 days and 2 months. A white layer around the droplets can be observed, evidencing the presence of n-HAp at the oil droplet surface. At 0 days, 

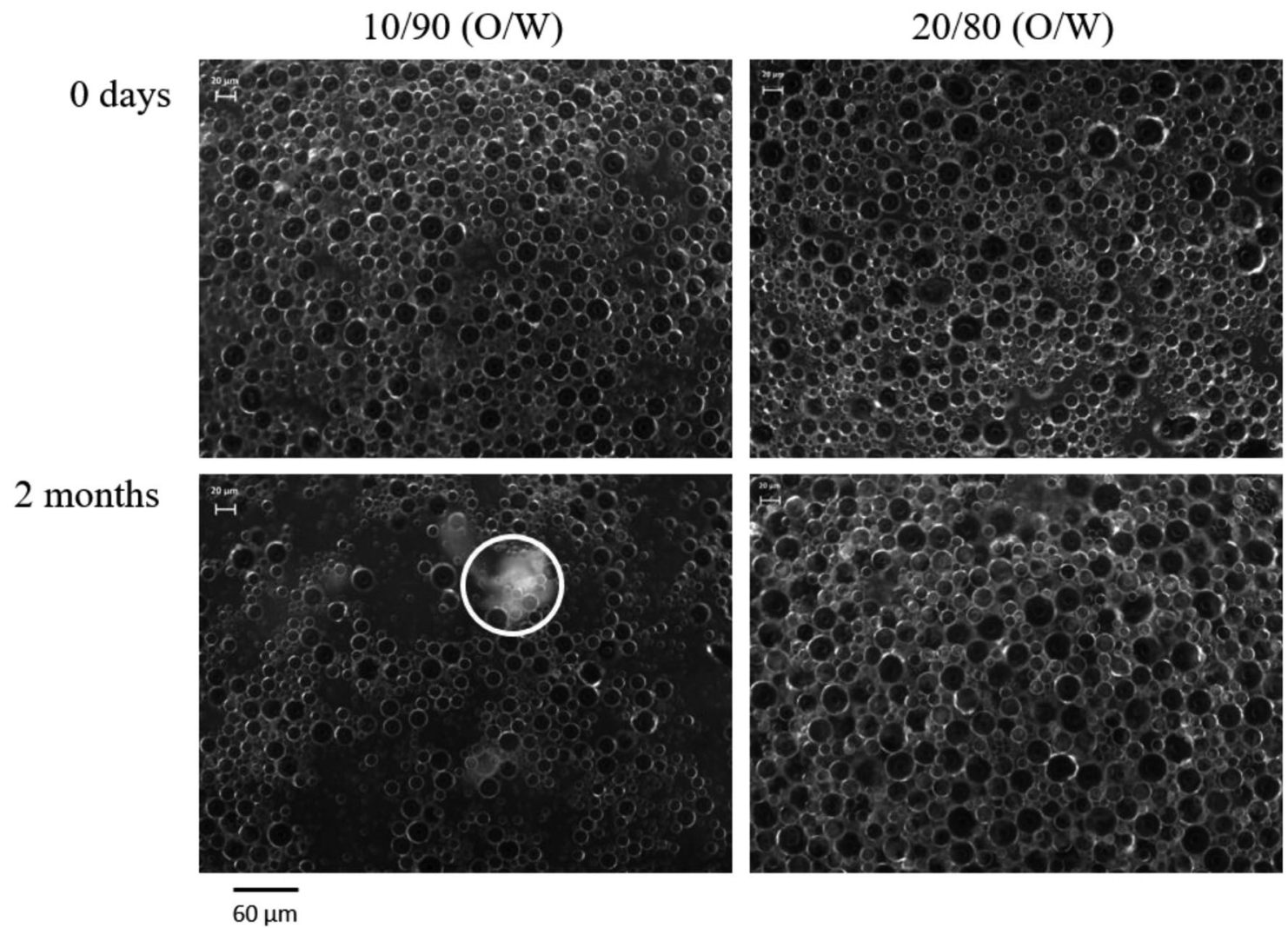

$60 \mu \mathrm{m}$

Figure 5. OM images, acquired in reflected light mode, of Pickering emulsions produced with different oil-water ratios and $\mathrm{n}$-HAp concentration of $5 \mathrm{wt} \%$. Magnification of $20 \times$. Circumference indicates white region associated with n-HAp agglomeration (observed as dark regions in the transmitted light mode).

images for both emulsions are similar, but after 2 months the emulsion using 10/90 ratio presents signs of instability and evidence of $\mathrm{n}$-HAp agglomeration. The emulsion prepared with a 20/80 ratio, even after 2 months, retains droplet's shape and n-HAp remains at the oil surface.

\subsection{Pickering emulsion stability prediction}

\subsubsection{Model development}

The objective here is to develop a model to estimate the concentration of $\mathrm{n}-\mathrm{HAp}$ required to produce a Pickering emulsion given the oil/water ratio, and also to predict the stability of these emulsions given the suspension concentration and the solid particles diameter. This model takes into account factors such as oil-water ratio, total solids concentration, droplet diameter and solid particles dimensions.

Considering the schematic representation of a Pickering emulsion shown in Figure 6, this model considers that:

- the emulsion is composed of an aqueous suspension of free solid particles, and an oleic phase of oil droplets surrounded by one or more layers of solid particles (Figure 6A);

- one oil droplet surrounded by one or more layers of solid particles is called a Pickering droplet (Figure 6B);

- free n-HAp particles and Pickering particles are in constant interaction through collisions creating a state of equilibrium;
- the oil droplets diameter, $d_{o}$, is much larger than the solid particle characteristic dimension, namely $d_{s}$, which is the typical length of n-HAp rod-like particles (at least 3 orders of magnitude);

- the volume occupied by the solid layer(s) in a Pickering particle is negligible compared with the volume of the oil droplet;

- the solid particles (n-HAp) are rod like structures (Figure 6C), approximated by a cylinder with height, $d_{s}$, as the characteristic dimension, and a shape factor of $5: 1 .^{[42]}$

The model considers that the stability of a Pickering emulsion depends on the degree of mobility of the solid particles, that is, on the ratio $l_{s}^{w} / d_{s}$, where $l_{s}^{w}$ is the mean distance between solid particles in suspension (aqueous phase), given by

$$
l_{s}^{w}=\left(\frac{m_{s}}{C_{s}^{w}}\right)^{1 / 3}
$$

where $m_{s}$ is the mass of one solid particle and $C_{s}^{w}$ is the concentration of solid particles in suspension (aqueous phase).

The mass of a single n-HAp particle is given by $m_{s}=$ $\rho_{s} v_{s}$, where $\rho_{s}$ is the solid density $\left(3160 \mathrm{Kg} / \mathrm{m}^{3}\right)$, and $v_{s}$ is the volume of a solid particle. Assuming a cylindrical shape for the n-HAp particle with 5:1 as shape factor, then

$$
v_{s}=\frac{\pi}{4}\left(\frac{d_{s}}{5}\right)^{2} d_{s}=\frac{\pi}{100} d_{s}^{3}
$$



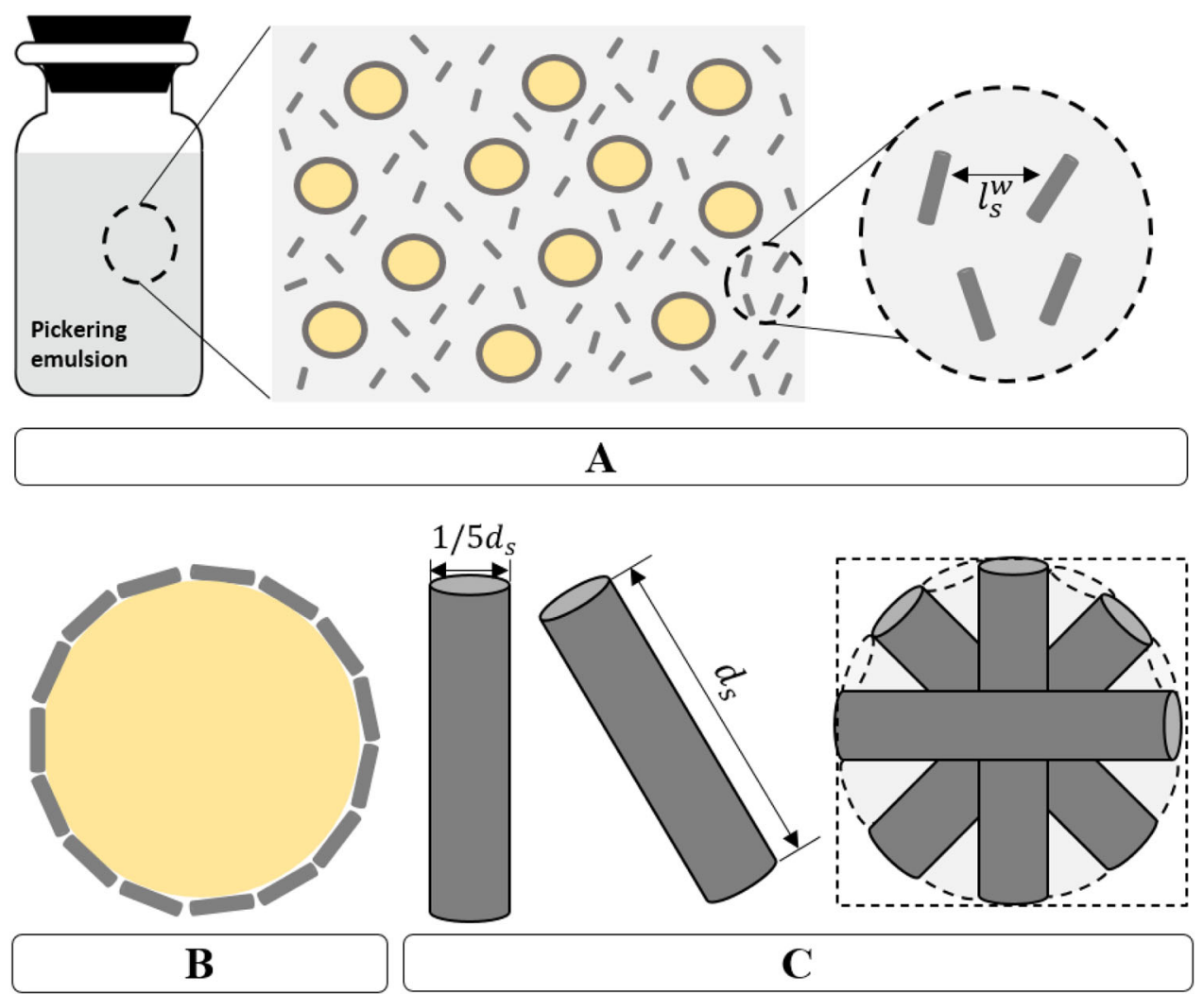

Figure 6. Schematic representation of a Pickering emulsion: A) Pickering emulsion with oil droplets surrounded by $n$-HAp, and aqueous phase composed with $n$ HAp suspended, B) Pickering droplet and C) represents the n-HAp structure as well as their dimensions.

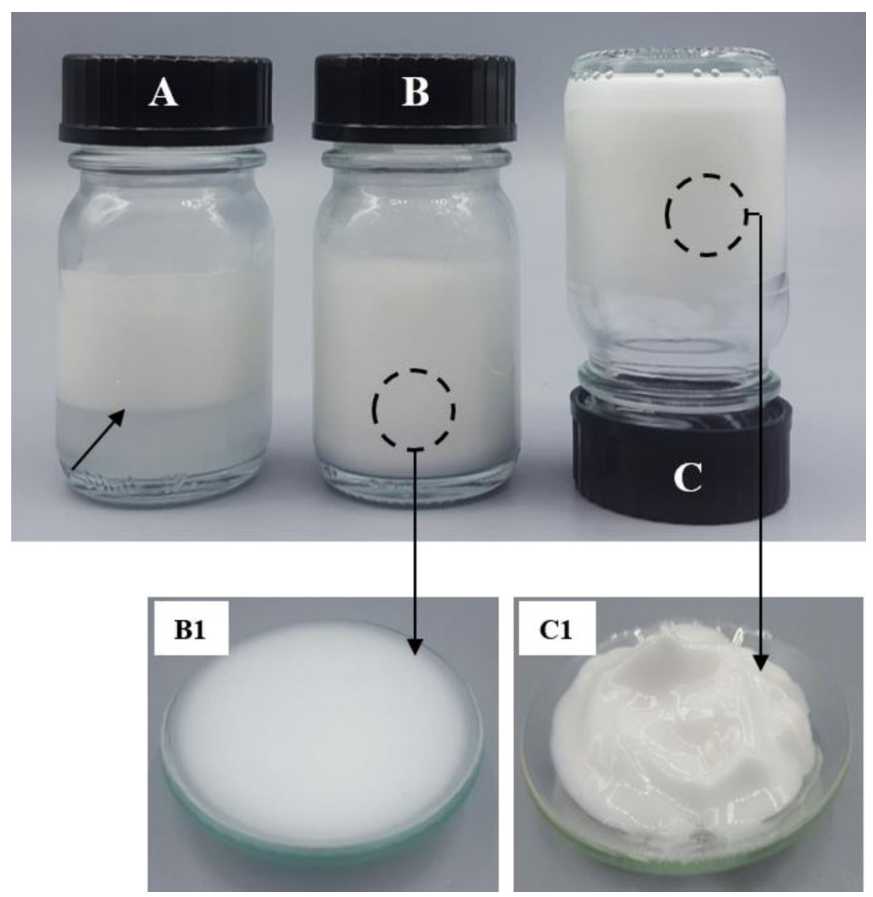

Figure 7. Comparison between different Pickering emulsions: A) unstable, B) and $\mathrm{B} 1$ ) stable and $\mathrm{C}$ ) and $\mathrm{C} 1$ ) gel stabilized with different $\mathrm{n}$-HAp concentrations $(1.5,5.0$ and $15 \mathrm{wt} \%$, respectively) and fixed oil-water ratio $(20 / 80, v / v)$.

The concentration of solid particles in the Pickering droplets, i.e., the particles that surround the oil droplets is given by

$$
C_{s}^{\alpha}=\frac{m_{s} N_{s}^{\alpha}}{V_{w}}
$$

where $N_{s}^{\alpha}$ is the minimum number of solid particles required to form $\alpha$ layers around the oil droplets and $V_{w}$ is the total volume of water. Since the solid particles are assumed to be much smaller than the oil droplets

$$
N_{s}^{\alpha}=\alpha n_{s} N_{o}
$$

where $N_{o}=6 V_{o} / \pi d_{o}^{3}$ is the number of oil droplets, $\alpha$ the number of layers and $V_{o}$ the total oil volume. The number of solid particles necessary to form a single layer is given by $n_{s}=a_{o} / a_{s}$, where $a_{o}=\pi d_{o}^{2}$ is the surface area of an oil droplet with diameter $d_{o}$, and $a_{s}$ is the area covered by a one solid particle. For a n-HAp particle and taking into account that each particle can take a random orientation at the oil surface, $a_{s}$ can be estimated assuming that a single solid particle covers a projected area equivalent to a square with side equal to $d_{s}$ (Figure 6C), and thus $a_{s}=d_{s}{ }^{2}$.

Combining all the previous relationships results in

$$
C_{s}^{\alpha}=\alpha \rho_{s} \frac{6 \pi}{100} \frac{d_{s}}{d_{o}} \frac{V_{o}}{V_{w}}=\alpha \rho_{s} \frac{6 \pi}{100} \frac{d_{s}}{d_{o}} \frac{X_{o}}{1-X_{o}}
$$

where $X_{o}$ and is the volume fraction of oil in the emulsion. In this relationship all values are known, except $d_{o}$ the diameter of the oil droplet and $\alpha$ the number of layers.

Finally, the concentration of solid particles in suspension (aqueous phase) can be obtained by

$$
C_{s}^{w}=C_{s}^{i n}-C_{s}^{\alpha}
$$

where $C_{s}^{\text {in }}$ is the initial formulation concentration of solid particles. 

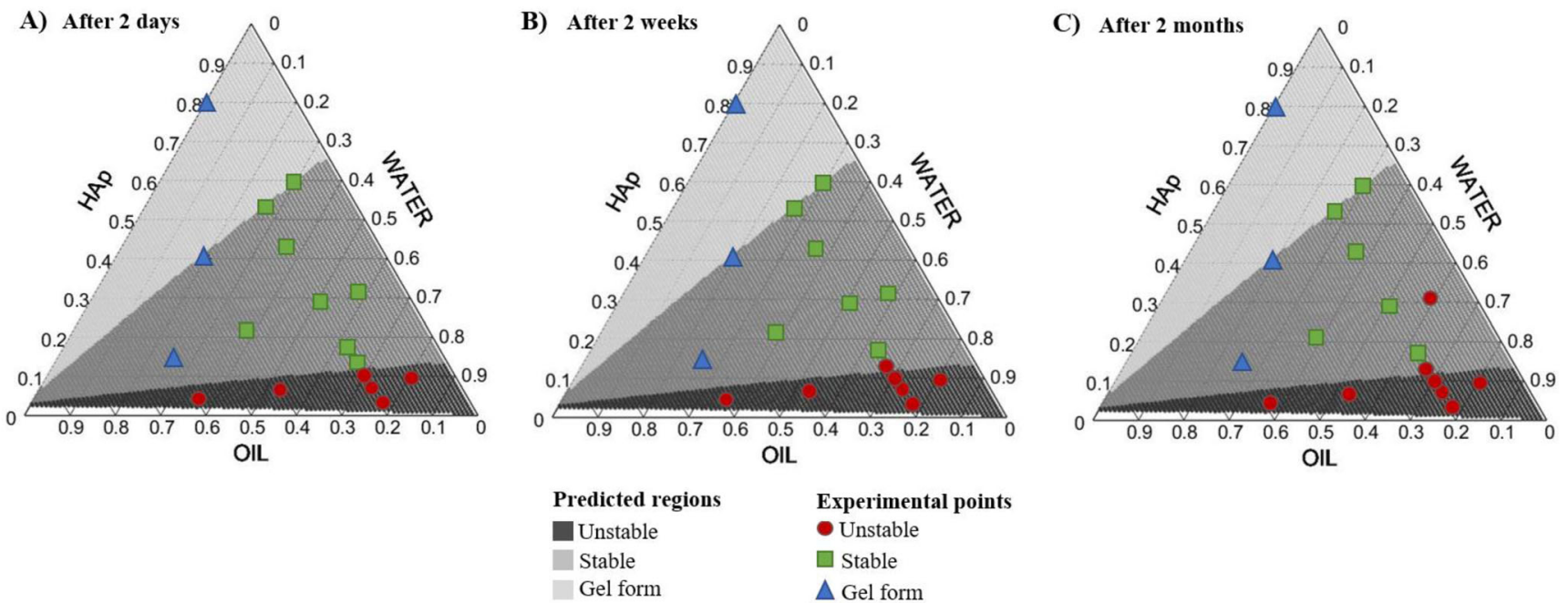

Figure 8. History of experimental point (2 days - 2 moths). Ternary diagram of O/W Pickering emulsions with $\mathrm{n}$-HAp and experimental points. Assumption: $I_{s}^{W} / d_{s}>1.7-$ unstable, $I_{s}^{W} / d_{s}<1-$ gel formation and $1 \leq I_{s}^{W} / d_{s} \leq 1.7-$ stable.

The model was applied to the $\mathrm{O} / \mathrm{W}$ ratio of $20 / 80$ (see Table 1) experimental data (2 days storage period) and the following limits were obtained

$$
\left\{\begin{array}{cl}
l_{s}^{w} / d_{s}>1.7 & \text { unstable } \\
1 \leq l_{s}^{w} / d_{s} \leq 1.7 & \text { stable } \\
l_{s}^{w} / d_{s}<1 & \text { gel formation }
\end{array}\right.
$$

In these calculations $d_{o}=18 \mu \mathrm{m}$ was taken as the average droplet diameter obtained through laser diffraction analysis. The parameter number of layers was assumed as constant, $\alpha=4$, in agreement with an estimated shell thickness of $200 \mathrm{~nm}$, as reported in Section 3.2.

The three types of formed emulsions (unstable, stable, and gel) are shown in Figure 7. The gel region should be understood as a stable region, but due to its high viscosity it may find constraints for some applications. Nevertheless, this type of formulations can find diverse uses, and thus the identification of the range of compositions at which it occurs is of interest.

\subsubsection{Model validation}

Ternary diagrams are convenient tools to represent threecomponent systems, as it is the case of emulsions (oil, water, and stabilizer). They have been used to represent systems besides thermodynamic equilibrium data, including emulsions, ${ }^{[43]}$ and more recently Pickering emulsions. ${ }^{[4]}$

The three stability regions - unstable, stable, gel - are identified in the ternary diagram of Figure 8A, where it is clear that the model is in good agreement with the data for other $\mathrm{O} / \mathrm{W}$ ratios. A single exception was observed for $X_{o}=$ 0.6 with the formation of a gel where a stable emulsion should have been formed. However, this result is in according to the results obtained by Xiao, et al. ${ }^{[45]}$ and $\mathrm{Zhu}$, et al., ${ }^{[46]}$ where the emulsion with higher oil ratio has a higher apparent viscosity compared with other ones with lower ratios. Furthermore, others previous works showed also a similar behavior of the viscosity increase with oil ratio increased. ${ }^{[47,48]}$
Figure $8 \mathrm{~B}, \mathrm{C}$ show the stability evolution of the Pickering emulsions after two weeks and two months, respectively. After the two-week period the stability of the emulsions was not changed, except for the emulsion with 20/80 oil-water ratio and $2 \mathrm{wt} \% \mathrm{n}-\mathrm{HAp}$ concentration. After two months, the stability of the $20 / 80,40 / 60$ and $60 / 40$ oil-water ratio emulsions was unchanged, with the exception of the one prepared with an oil-water ratio of 10/90 and an n-HAp content of 5\%, which became unstable. For low oil content, the observed phase separation may be mostly due to the density difference between the two phases (oil and water) combined with a lower droplet concentration. The use of high oil-water ratios increases the droplets concentration, that become more tightly together delaying phase separation by preventing their movement. In case of low oil-water ratios, n-HAp content increase can also promote stabilization, i.e., n-HAp particles not participating in the stabilization (they might be in excess) can act as an external thickener. This might be the case of the 10/90 formulation using 10\% n-HAp.

\subsection{Pickering emulsion rheology study}

The rheological properties of Pickering emulsions can be related with their performance and storage stability. The effect of the n-HAp concentration was studied, maintaining the oil-water ratio as $20 / 80(v / v)$, in terms of the viscosity and elastic $\left(G^{\prime}\right)$ and loss $\left(G^{\prime \prime}\right)$ modulus through steady-state flow and dynamic oscillatory measurements, respectively.

The obtained results are presented in Figure 9. Figure 9A shows the viscosity of the Pickering emulsions stabilized with different $\mathrm{n}$-HAp concentrations. It can be perceived that the Pickering emulsions have a n-HAp concentration dependent behavior since the viscosity increases as the $n$ HAp concentration increases. Similar results were obtained by Xiao, et al. ${ }^{[45]}$ that also observed an increase of the Pickering emulsion viscosity as the concentration of kafirin particles increased. 

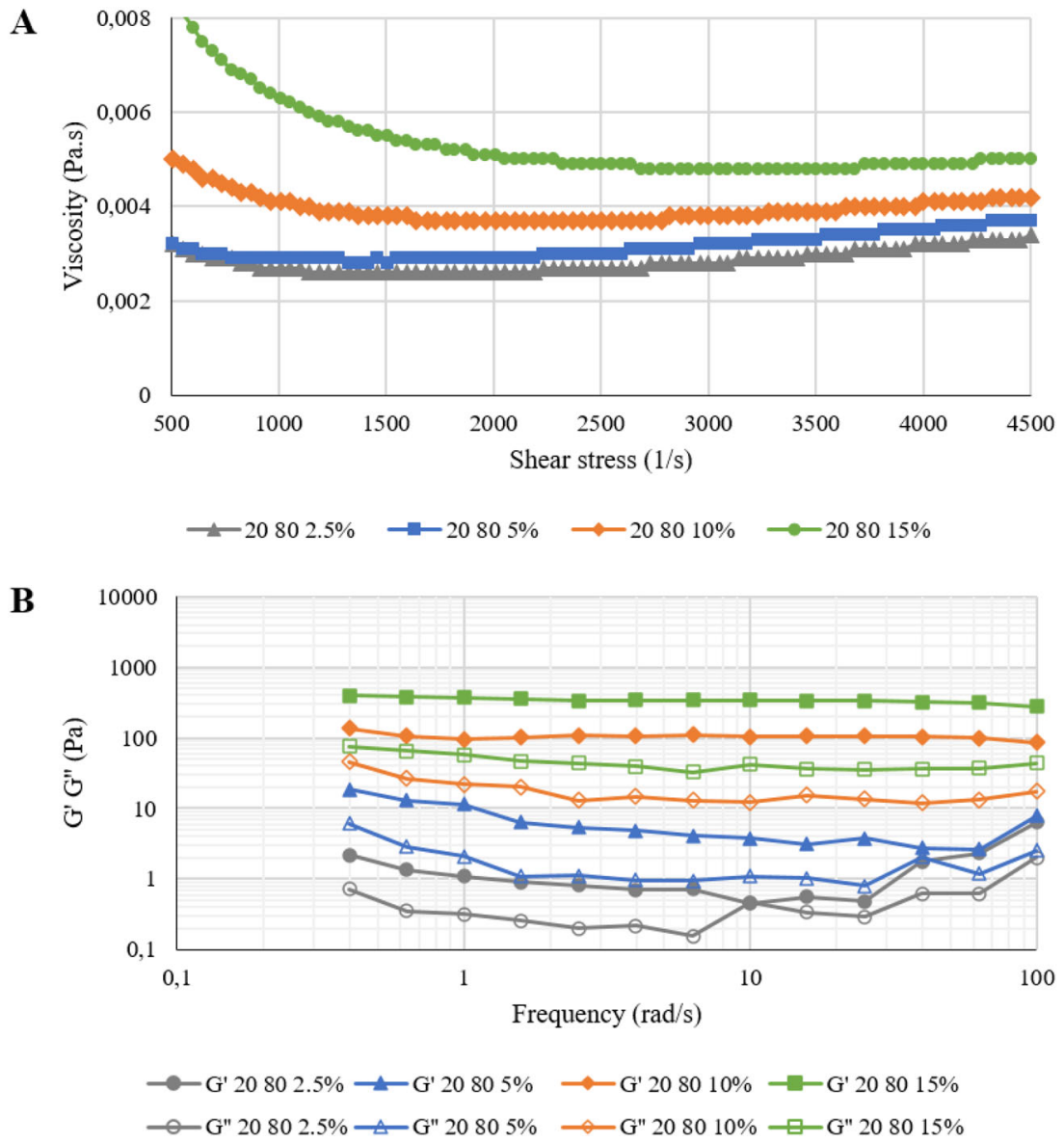

Figure 9. Rheological properties of Pickering emulsions stabilized with different $n$-HAp concentrations $(2.5,5,10$ and 15 wt $\%)$ and fixed oil-water ratio (20/80, $v / v)$ : A) Pickering emulsion viscosity versus shear rate and B) oscillatory frequency sweep curves: $G^{\prime}$ storage modulus and $G^{\prime \prime}$ loss modulus.

The formation of the gel-like structures in Pickering emulsions was evaluated through oscillatory measurements. Figure $9 \mathrm{~B}$ shows $\mathrm{G}^{\prime}$ and $\mathrm{G}^{\prime \prime}$ as a function of frequency. For all measurements, it is observed that both moduli were nearly independent of the frequency (for range $0.3-100 \mathrm{rad} / \mathrm{s}$ ), but $\mathrm{G}^{\prime}$ is always higher than $G^{\prime \prime}$ (in magnitude) over the tested frequency range. This result indicates that the rheological behavior of the Pickering emulsions was predominantly, which is compatible with the development of gel-like networks. The development of the gel-like networks on Pickering emulsions is influenced by the n-HAp concentration. This behavior was previously reported in studies dealing with other Pickering stabilizers such as kafirin ${ }^{[45]}$ and cellulose. ${ }^{[49]}$

In general, the increase of the n-HAp concentration promotes the interactions between the free-particles leading to the formation of a structural network, avoiding phase separation. The results were reproducible for the other tested oilwater ratios (data not shown). These findings show that the stability of the Pickering emulsions can be improved by increasing the n-HAp concentration, or oil volume fraction, which is in agreement with the model predictions.

\section{Conclusions}

Hydroxyapatite is a biomaterial that has been used in different fields. Recently it has been applied in Pickering emulsions production, mostly following a strategy of combining it with polymers such as poly- $\varepsilon$-caprolactone and poly-L-lactic acid. ${ }^{[10,15]}$ In this study, a commercial n-HAp paste (NanoXIM-CarePaste) was used in the preparation of the Pickering emulsions. Emulsion stability was studied as a function of processing parameters, such as oil-water ratio, and $n-H A p$ content. According to the drop test, independently of the used oil-water ratio or n-HAp content, all the produced Pickering emulsions were of $\mathrm{O} / \mathrm{W}$ type. The microscopy evaluation by optical and cryo-SEM confirmed the formation of spherical Pickering droplets, and the presence of n-HAp attached at the oil droplet's surface (through cryo-SEM), corroborating an oil core-HAp shell morphology, similarly to a microcapsule.

In this work, a wide range of compositions, namely oilwater ratios (10/90-60/40, v/v) and n-HAp concentrations $(0.5-15$, wt $\%)$ were studied. In a general way, it was observed that when the n-HAp content increases a decrease of the mean droplet size was observed, and that the oil-water ratio increase favored the increase of the mean droplet size.

According to the developed model, three regions in a ternary phase diagram were defined (unstable, stable and gel), and the experimental data was generally in good agreement with the model. By using this model, it is possible to predict the type of emulsion to be formed based on the used formulation, as well as to predict its stability. Face to the analyzed timeframe the model is reliable up to two weeks; only after 2 months differences were found. Rheological studies show 
that the stability of the Pickering emulsions can be improved by increasing the n-HAp concentration, or the oil volume fraction, which is in agreement with the model predictions.

This work is a step forward in the field of synthetic surfactants substitution contributing to the sustainable development of emulsions. Pickering particles emerge as an alternative to traditional emulsifiers, which have been related with harmful health effects. ${ }^{[50,51]}$ The use of a commercial $\mathrm{n}$-HAp is an important achievement since the stabilization is guaranteed by a native n-HAp that was not processed with solvents, conventional emulsifiers, or combined with other compounds to improve particle's wettability, avoiding issues such as emulsion contamination. Further studies are under development in order to produce these Pickering emulsions in continuous mode (increasing production scale) through the use of low energy devices. These Pickering emulsions can be used as versatile food-grade vehicles for the encapsulation of hydrophobic compounds such as vitamins, which is, technologically, an important issue, namely to increase their bioavailability.

\section{Acknowledgements}

Authors thank Fluidinova S.A. (www.fluidinova.com) for providing nanoXIM-CarePaste, and the Centro de Materiais da Universidade do Porto (CEMUP) for the services provided with cryo-SEM analysis.

\section{Disclosure statement}

There are no conflicts to declare.

\section{Funding}

This work was financially supported by: Associate Laboratory LSRELCM - UIDB/50020/2020 - funded by national funds through FCT/ MCTES (PIDDAC). To Foundation for Science and Technology (FCT, Portugal) for financial support by national funds FCT/MCTES to CIMO (UIDB/00690/2020). Andreia Ribeiro acknowledges her PhD fellowship funded by Project NORTE-08-5369-FSE-000028, supported by N2020, under PT2020, through ESF.

\section{ORCID}

Andreia Ribeiro (D) http://orcid.org/0000-0003-1352-691X Yaidelin A. Manrique (D) http://orcid.org/0000-0002-7053-373X Isabel C.F.R Ferreira (iD http://orcid.org/0000-0003-4910-4882 Maria Filomena Barreiro (iD http://orcid.org/0000-0002-6844-333X José Carlos B. Lopes (D) http://orcid.org/0000-0001-6127-6340 Madalena M. Dias (D) http://orcid.org/0000-0003-1208-1496

\section{References}

[1] Yang, Y.; Fang, Z.; Chen, X.; Zhang, W.; Xie, Y.; Chen, Y.; Liu, Z.; Yuan, W. An Overview of Pickering Emulsions: SolidParticle Materials, Classification, Morphology, and Applications. Front. Pharmacol. 2017, 8, 287-287. DOI: 10.3389/fphar.2017. 00287.

[2] Berton-Carabin, C. C.; Schroën, K. Pickering Emulsions for Food Applications: Background, Trends, and Challenges. Annu. Rev. Food Sci. Technol. 2015, 6, 263-297. DOI: 10.1146/ annurev-food-081114-110822.
[3] Dickinson, E. Use of Nanoparticles and Microparticles in the Formation and Stabilization of Food Emulsions. Trends Food Sci. Tech. 2012, 24, 4-12. DOI: 10.1016/j.tifs.2011.09.006.

[4] Ramsden, W. Separation of Solids in the Surface-Layers of Solutions and 'Suspensions' (Observations on SurfaceMembranes, Bubbles, Emulsions, and Mechanical Coagulation). - Preliminary Account. Proc. R. Soc. London 1903, 72, 156-164. DOI: $10.1098 /$ rspl.1903.0034.

[5] Pickering, S. U. CXCVI.-Emulsions. J. Chem. Soc. A 1907, 91, 2001-2021. DOI: 10.1039/CT9079102001.

[6] Hu, B.; Zhao, C.; Jin, X.; Wang, H.; Xiong, J.; Tan, J. Antagonistic Effect in Pickering Emulsion Stabilized by Mixtures of Hydroxyapatite Nanoparticles and Sodium Oleate. Colloi. Surf. A 2015, 484, 278-287. DOI: 10.1016/j.colsurfa.2015. 08.009 .

[7] Albert, C.; Beladjine, M.; Tsapis, N.; Fattal, E.; Agnely, F.; Huang, N. Pickering Emulsions: Preparation Processes, Key Parameters Governing Their Properties and Potential for Pharmaceutical Applications. J. Control Release 2019, 309, 302-332. DOI: 10.1016/j.jconrel.2019.07.003.

[8] Son, H. A.; Yoon, K. Y.; Lee, G. J.; Cho, J. W.; Choi, S. K.; Kim, J. W.; Im, K. C.; Kim, H. T.; Lee, K. S.; Sung, W. M. The Potential Applications in Oil Recovery with Silica Nanoparticle and Polyvinyl Alcohol Stabilized Emulsion. J. Petrol. Sci. Eng. 2015, 126, 152-161. DOI: 10.1016/j.petrol.2014.11.001.

[9] Frelichowska, J.; Bolzinger, M.-A.; Valour, J.-P.; Mouaziz, H.; Pelletier, J.; Chevalier, Y. Pickering w/o Emulsions: Drug Release and Topical Delivery. Int. J. Pharm. 2009, 368, 7-15. DOI: 10.1016/j.ijpharm.2008.09.057.

[10] Zhang, M.; Wang, A.; Li, J.; Song, N.; Song, Y.; He, R. Factors Influencing the Stability and Type of Hydroxyapatite Stabilized Pickering Emulsion. Mater. Sci. Eng. C Mater. Biol. Appl. 2017, 70, 396-404. DOI: 10.1016/j.msec.2016.09.007.

[11] Björkegren, S.; Nordstierna, L.; Törncrona, A.; Palmqvist, A. Hydrophilic and Hydrophobic Modifications of Colloidal Silica Particles for Pickering Emulsions. J. Colloid Interface Sci. 2017, 487, 250-257. DOI: 10.1016/j.jcis.2016.10.031.

[12] Barkhordari, M. R.; Fathi, M. Production and Characterization of Chitin Nanocrystals from Prawn Shell and Their Application for Stabilization of Pickering Emulsions. Food Hydrocolloid 2018, 82, 338-345. DOI: 10.1016/j.foodhyd.2018.04.030.

[13] Meshulam, D.; Lesmes, U. Responsiveness of Emulsions Stabilized by Lactoferrin Nano-Particles to Simulated Intestinal Conditions. Food Funct. 2014, 5, 65-73. DOI: 10.1039/ C3FO60380F.

[14] Schröder, A.; Sprakel, J.; Schroën, K.; Spaen, J. N.; BertonCarabin, C. C. Coalescence Stability of Pickering Emulsions Produced with Lipid Particles: A Microfluidic Study. J. Food Eng. 2018, 234, 63-72. DOI: 10.1016/j.jfoodeng.2018.04.007.

[15] Zhang, M.; Wang, A.; Li, J.; Song, N. Effect of Stearic Acid Modified HAp Nanoparticles in Different Solvents on the Properties of Pickering Emulsions and HAp/PLLA Composites. Mater. Sci. Eng. C Mater. Biol. Appl. 2017, 79, 255-261. DOI: 10.1016/j.msec.2017.05.045.

[16] Fujii, S.; Okada, M.; Nishimura, T.; Maeda, H.; Sugimoto, T.; Hamasaki, H.; Furuzono, T.; Nakamura, Y. HydroxyapatiteArmored Poly( $\varepsilon$-Caprolactone) Microspheres and Hydroxyapatite Microcapsules Fabricated via a Pickering Emulsion Route. J. Colloid Interface Sci. 2012, 374, 1-8. DOI: 10.1016/j.jcis.2012.01.058.

[17] Okada, M.; Maeda, H.; Fujii, S.; Nakamura, Y.; Furuzono, T. Formation of Pickering Emulsions Stabilized via Interaction between Nanoparticles Dispersed in Aqueous Phase and Polymer End Groups Dissolved in Oil Phase. Langmuir 2012, 28, 9405-9412. DOI: 10.1021/la3015964.

[18] Samanta, A.; Takkar, S.; Kulshreshtha, R.; Nandan, B.; Srivastava, R. K. Hydroxyapatite Stabilized Pickering Emulsions of Poly( $\varepsilon$-Caprolactone) and Their Composite Electrospun Scaffolds. Colloi. Surf. A 2017, 533, 224-230. DOI: 10.1016/j. colsurfa.2017.09.001. 
[19] Hu, Y.; Zou, S.; Chen, W.; Tong, Z.; Wang, C. Mineralization and Drug Release of Hydroxyapatite/Poly(l-Lactic Acid) Nanocomposite Scaffolds Prepared by Pickering Emulsion Templating. Colloids Surf. B Biointerfaces 2014, 122, 559-565. DOI: 10.1016/j.colsurfb.2014.07.032.

[20] Liu, F.; Tang, C.-H. Soy Glycinin as Food-Grade Pickering Stabilizers: Part. I. Structural Characteristics, Emulsifying Properties and Adsorption/Arrangement at Interface. Food Hydrocolloid 2016, 60, 606-619. DOI: 10.1016/j.foodhyd.2015. 04.025 .

[21] Menon, V. B.; Wasan, D. T. Characterization of Oil-Water Interfaces Containing Finely Divided Solids with Applications to the Coalescence of Water-in-Oil Emulsions: A Review. Colloid. Surf. 1988, 29, 7-27. doi:https://doi.org/10.1016/01666622. (88)80169-0 DOI: 10.1016/0166-6622(88)80169-0.

[22] Hodge, S. M.; Rousseau, D. Continuous-Phase Fat Crystals Strongly Influence Water-in-Oil Emulsion Stability. J. Amer. Oil Chem. Soc. 2005, 82, 159-164. DOI: 10.1007/s11746-0055166-4.

[23] Binks, B. P.; Olusanya, S. O. Pickering Emulsions Stabilized by Coloured Organic Pigment Particles. Chem. Sci. 2017, 8, 708-723. DOI: $10.1039 / \mathrm{c} 6 \mathrm{sc} 03085 \mathrm{~h}$.

[24] Binks, B. P.; Clint, J. H. Solid Wettability from Surface Energy Components: Relevance to Pickering Emulsions. Langmuir 2002, 18, 1270-1273. DOI: 10.1021/la011420k.

[25] Linke, C.; Drusch, S. Pickering Emulsions in Foods Opportunities and Limitations. Crit. Rev. Food Sci. Nutr. 2018, 58, 1971-1985. DOI: 10.1080/10408398.2017.1290578.

[26] Rayner, M. Current Status on Novel Ways for Stabilizing Food Dispersions by Oleosins, Particles and Microgels. Curr. Opin. Food Sci. 2015, 3, 94-109. DOI: 10.1016/j.cofs.2015.05.006.

[27] Tcholakova, S.; Denkov, N. D.; Lips, A. Lips, A. Comparison of Solid Particles, Globular Proteins and Surfactants as Emulsifiers. Phys. Chem. Chem. Phys. 2008, 10, 1608-1627. DOI: 10.1039/ b715933c.

[28] Arditty, S.; Whitby, C. P.; Binks, B. P.; Schmitt, V.; LealCalderon, F. Some General Features of Limited Coalescence in Solid-Stabilized Emulsions. Eur. Phys. J. E Soft Matter 2003, 11, 273-281. DOI: 10.1140/epje/i2003-10018-6.

[29] Kalashnikova, I.; Bizot, H.; Cathala, B.; Capron, I. New Pickering Emulsions Stabilized by Bacterial Cellulose Nanocrystals. Langmuir 2011, 27, 7471-7479. DOI: 10.1021/ la200971f.

[30] Xiao, J.; Li, Y.; Huang, Q. Recent Advances on Food-Grade Particles Stabilized Pickering Emulsions: Fabrication, Characterization and Research Trends. Trends Food Sci. Tech. 2016, 55, 48-60. DOI: 10.1016/j.tifs.2016.05.010.

[31] Wu, J.; Ma, G.-H. Recent Studies of Pickering Emulsions: Particles Make the Difference. Small 2016, 12, 4633-4648. DOI: 10.1002/smll.201600877.

[32] Aveyard, R.; Binks, B. P.; Clint, J. H. Emulsions Stabilised Solely by Colloidal Particles. Adv. Colloid Interface Sci. 2003, 100-102, 503-546. DOI: 10.1016/S0001-8686. (02)00069-6

[33] Silva, V. M. T. M.; Quadros, P. A.; Laranjeira, P. E. M. S. C.; Dias, M. M.; Lopes, J. C. B. A Novel Continuous Industrial Process for Producing Hydroxyapatite Nanoparticles. J. Dispersion Sci. Technol. 2008, 29, 542-547. DOI: 10.1080/ 01932690701728924.

[34] Ruphuy, G.; Saralegi, A.; Lopes, J. C.; Dias, M. M.; Barreiro, M. F. Spray Drying as a Viable Process to Produce NanoHydroxyapatite/Chitosan (n-HAp/CS) Hybrid Microparticles Mimicking Bone Composition. Adv. Powder Technol. 2016, 27, 575-583. DOI: 10.1016/j.apt.2016.02.010.

[35] Binks, B. P.; Kirkland, M. Interfacial Structure of SolidStabilised Emulsions Studied by Scanning Electron Microscopy. Phys. Chem. Chem. Phys. 2002, 4, 3727-3733. DOI: 10.1039/ b110031a.

[36] Griffith, C.; Daigle, H. Manipulation of Pickering Emulsion Rheology Using Hydrophilically Modified Silica Nanoparticles in Brine. J. Colloid Interface Sci. 2018, 509, 132-139. DOI: 10. 1016/j.jcis.2017.08.100.

[37] Hu, Y.-Q.; Yin, S.-W.; Zhu, J.-H.; Qi, J.-R.; Guo, J.; Wu, L.-Y.; Tang, C.-H.; Yang, X.-Q. Fabrication and Characterization of Novel Pickering Emulsions and Pickering High Internal Emulsions Stabilized by Gliadin Colloidal Particles. Food Hydrocolloid 2016, 61, 300-310. DOI: 10.1016/j.foodhyd.2016. 05.028.

[38] Ashby, N. P.; Binks, B. P. Pickering Emulsions Stabilised by Laponite Clay Particles. Phys. Chem. Chem. Phys. 2000, 2, 5640-5646. DOI: 10.1039/b007098j.

[39] Yang, F.; Liu, S.; Xu, J.; Lan, Q.; Wei, F.; Sun, D. Pickering Emulsions Stabilized Solely by Layered Double Hydroxides Particles: The Effect of Salt on Emulsion Formation and Stability. J. Colloid Interface Sci. 2006, 302, 159-169. DOI: 10. 1016/j.jcis.2006.06.015.

[40] Yang, T.; Zheng, J.; Zheng, B.-S.; Liu, F.; Wang, S.; Tang, C.-H. High Internal Phase Emulsions Stabilized by Starch Nanocrystals. Food Hydrocolloid 2018, 82, 230-238. DOI: 10. 1016/j.foodhyd.2018.04.006.

[41] Ou, W.; Ye, C.; Zhang, Q.; Zhu, H.; Zhang, W. Pickering Emulsions Stabilized by Hydrophobically Modified Hemp Powders: The Effect of Formula Compositions on Emulsifying Capability and Stability. J. Dispersion Sci. Technol. 2019, 1-9. DOI: 10.1080/01932691.2019.1653196.

[42] Gomes, P. J.; Silva, V. M.; Quadros, P. A.; Dias, M. M.; Lopes, J. C. B. A Highly Reproducible Continuous Process for Hydroxyapatite Nanoparticles Synthesis. J. Nanosci. Nanotechnol. 2009, 9, 3387-3395. DOI: 10.1166/jnn.2009.ns06.

[43] Kumar, H.; Kumar, V. Ultrasonication Assisted Formation and Stability of Water-in-Oil Nanoemulsions: Optimization and Ternary Diagram Analysis. Ultrason. Sonochem. 2018, 49, 79-88. DOI: 10.1016/j.ultsonch.2018.07.022.

[44] Rincón-Fontán, M.; Rodríguez-López, L.; Vecino, X.; Cruz, J. M.; Moldes, A. B. Study of the Synergic Effect between Mica and Biosurfactant to Stabilize Pickering Emulsions Containing Vitamin E Using a Triangular Design. J. Colloid Interface Sci. 2019, 537, 34-42. DOI: 10.1016/j.jcis.2018.10.106.

[45] Xiao, J.; Wang, Xa.; Perez Gonzalez, A. J.; Huang, Q. Kafirin Nanoparticles-Stabilized Pickering Emulsions: Microstructure and Rheological Behavior. Food Hydrocolloid 2016, 54, 30-39. DOI: $10.1016 /$ j.foodhyd.2015.09.008.

[46] Zhu, Y. Q.; Chen, X.; McClements, D. J.; Zou, L.; Liu, W. Pickering-Stabilized Emulsion Gels Fabricated from Wheat Protein Nanoparticles: Effect of $\mathrm{pH}, \mathrm{NaCl}$ and Oil Content. $J$. Dispersion Sci. Technol. 2018, 39, 826-835. DOI: 10.1080/ 01932691.2017.1398660.

[47] Dai, L.; Sun, C.; Wei, Y.; Mao, L.; Gao, Y. Characterization of Pickering Emulsion Gels Stabilized by Zein/Gum Arabic Complex Colloidal Nanoparticles. Food Hydrocolloid 2018, 74 239-248. DOI: 10.1016/j.foodhyd.2017.07.040.

[48] Shao, Y.; Tang, C.-H. Gel-like Pea Protein Pickering Emulsions at $\mathrm{pH} 3.0$ as a Potential Intestine-Targeted and SustainedRelease Delivery System for $\beta$-Carotene. Food Res. Int. 2016, 79, 64-72. DOI: 10.1016/j.foodres.2015.11.025.

[49] Li, Z.; Wu, H.; Yang, M.; Xu, D.; Chen, J.; Feng, H.; Lu, Y.; Zhang, L.; Yu, Y.; Kang, W. Stability Mechanism of O/W Pickering Emulsions Stabilized with Regenerated Cellulose. Carbohydr. Polym. 2018, 181, 224-233. DOI: 10.1016/j.carbpol. 2017.10.080.

[50] Chassaing, B.; Koren, O.; Goodrich, J. K.; Poole, A. C.; Srinivasan, S.; Ley, R. E.; Gewirtz, A. T. Dietary Emulsifiers Impact the Mouse Gut Microbiota Promoting Colitis and Metabolic Syndrome. Nature 2015, 519, 92-96. DOI: 10.1038/ nature14232.

[51] Di Sotto, A.; Maffei, F.; Hrelia, P.; Di Giacomo, S.; Pagano, E.; Borrelli, F.; Mazzanti, G. Genotoxicity Assessment of Some Cosmetic and Food Additives. Regul. Toxicol. Pharm. 2014, 68, 16-22. DOI: 10.1016/j.yrtph.2013.11.003. 